\title{
Survival Analysis of Patients with
}

\section{Alzheimer's Disease: A Study Based on Data from the Korean National Health} Insurance Services' Senior Cohort Database

\author{
Tae Ho Huh', Jong Lull Yoon ${ }^{1,2, *}$, Jung Jin Cho ${ }^{1,2}$, Mee Young Kim ${ }^{1,2}$, Young Soo Jü \\ 'Department of Family Medicine, Hallym University Dongtan Sacred Heart Hospital, Hwaseong, Korea \\ ${ }^{2}$ Department of Family Medicine, Hallym University College of Medicine, Chuncheon, Korea \\ ${ }^{3}$ Department of Occupational and Environmental Medicine, Hallym University College of Medicine, Chuncheon, Korea
}

Background: Korea's rapidly aging population has experienced a sharp rise in the prevalence of dementia. Patients with Alzheimer's disease (AD), which is estimated to be about three-quarters of all patients with dementia, tend to have higher mortality rates compared with patients without Alzheimer's disease. In this study, a survival analysis of patients with $\mathrm{AD}$ was conducted in order to provide knowledge to those who provide medical care to these patients. Methods: Data on individuals over 65 years old in 2004 were extracted from the Korean National Health Insurance Services' Senior Cohort database (2002-2013). The subjects were 209,254 patients, including 2,695 who were first diagnosed with $\mathrm{AD}$ (the $\mathrm{AD}$ group) and 206,559 that had not been diagnosed with the disease (non-AD group). To investigate the independent effect of $\mathrm{AD}$ on survival, the Cox proportional-hazards model, hazard ratios (confidence interval of 95\%), and the Kaplan-Meier method were used.

Results: Mean survival time in the $\mathrm{AD}$ group was $5.3 \pm 3.3$ years, which was about 2.5 years shorter than that in the non- $\mathrm{AD}$ group (7.8 \pm 2.4 years). The mortality rate in the $\mathrm{AD}$ group (66.3\%) was higher than that in the non- $\mathrm{AD}$ group (26.3\%). The adjusted hazard ratio in the $\mathrm{AD}$ group was 2.5 and, therefore, it was found that the $\mathrm{AD}$ group had a 2.5 -fold higher risk of death than the non-AD group.

Conclusion: Overall, $\mathrm{AD}$ has a large, independent impact on survival. Survival time was shorter, and the mortality rate and risk were generally higher in the $\mathrm{AD}$ group, compared with the non- $\mathrm{AD}$ group.

Keywords: Alzheimer Disease; Database; Survival Analysis; Mortality

Received: July 20, 2018, Revised: September 6, 2018, Accepted: September 10, 2018

*Corresponding Author: Jong-Lull Yoon https://orcid.org/0000-0001-8931-0256

Tel: +82-31-8086-2390, Fax: +82-31-8086-2709, E-mail: lull@hallym.or.kr 


\section{INTRODUCTION}

As indicated in "Towards a dementia plan: a WHO guide" published by the World Health Organization in 2018, ${ }^{1)}$ there are about 50 million patients with dementia around the world and dementia is the seventh leading cause of death globally. However, Alzheimer's disease (AD) is still incurable. ${ }^{2-4)}$ Korea was officially declared an aged society in 2017, and the country's rapidly aging population is experiencing a sharp rise in the prevalence of dementia. ${ }^{5,6)}$ According to the Korean Dementia Observatory 2017, the number of patients with dementia is about 660,000 which is high enough to accounts for approximately $9.8 \%$ of the total Korean population over 65 years of age. ${ }^{7)}$ Patients with $\mathrm{AD}$ are estimated to make up three-quarters of the total patients with dementia. Among the $17.9 \%$ of the total dementia deaths, patients with $\mathrm{AD}$ account for the largest percentage at 9.4\%. ${ }^{7}$ Therefore, management of the population with $\mathrm{AD}$ has become more important than ever. Concern about dementia is greater than ever in Korea, and the ratio of treatment and management has increased. However, there is still a lack of support services, and it is imperative to be strengthened policies for dementia care ${ }^{8,9)}$ Moreover, there have been few related Korean studies, and those Korean studies that currently exist have limitations such as small sample sizes or short follow-up durations. In this study, a survival analysis of patients with $\mathrm{AD}$ was conducted using data from the National Health Insurance Services' Senior Cohort database (2002-2013), a database representative of the elderly population of Korea that can provide more generalizable results.

\section{METHODS}

\section{Subjects}

Data on individuals aged 65 years or older in 2004 were extracted from the Korean National Health Insurance Services' Senior Cohort database (2002-2013). The subjects were 209,254 individuals, including 2,695 with a first diagnoses of $\mathrm{AD}$ during the year 2004 (the $\mathrm{AD}$ group) and 206,559 without $\mathrm{AD}$ (the non-AD group) (Figure 1). In order to select the population diagnosed with $\mathrm{AD}$ (International Classification of
Diseases, 10th revision [ICD-10] codes F00, F000-F002, F009, F03, G30, G300-G301, G308, and G309) for the first time in life, in 2004, all patients formerly diagnosed with $\mathrm{AD}$ were excluded. We also excluded patients with cerebral vascular accident (CVA; ICD-10 codes I60-I69 and G46), cardiovascular disease (CVD; ICD-10 codes I20-I25), and cancer (ICD-10 codes C00-C97 and D01-D09), which have significant impact on death, from 2002 to 2004. In addition, during the same period, all deceased patients were excluded. Additionally, all patients newly diagnosed with AD during the observation period (2005-2013) were excluded from the non- $\mathrm{AD}$ (control) group.

\section{Observation Period}

The length of the observation period was 9 years (from January 1, 2005 to December 31, 2013). In the case of death within the period, the survival time to the day of death was converted to the number of years. For further analysis, from the date of the first $\mathrm{AD}$ diagnosis in 2004 to the date of death, the survival days were also converted into years.

\section{Covariates and Statistical Analysis}

To investigate the independent effect of AD on mortality risk, factors associated with survival, such as gender, age, income level, and the three most common major chronic diseases (i.e., hypertension, diabetes, and dyslipidemia) were used as adjustment variables. In addition, the Cox proportional-hazard model was used to find correlation among the factors, and hazard ratio (HR) and 95\% confidence interval (CI) were calculated. In addition, stratification analysis was conducted for each variable to examine the effect of $\mathrm{AD}$ on survival in more detail. Mortality rates were analyzed by gender and age during the study period, and the Kaplan-Meier method was used to compare the survival times and the survival rates. Statistical significance level was set at $\mathrm{P}<0.05$, and all analyses were performed using SAS ver. 9.4 (SAS Institute Inc., Cary, NC, USA). The protocol of this study was approved by the Institutional Review Board of Hallym University Dongtan Sacred Heart Hospital (IRB approval no., 2018-05-007), and the requirement for informed consent from individual patients was omitted because of the retrospective design of this study.

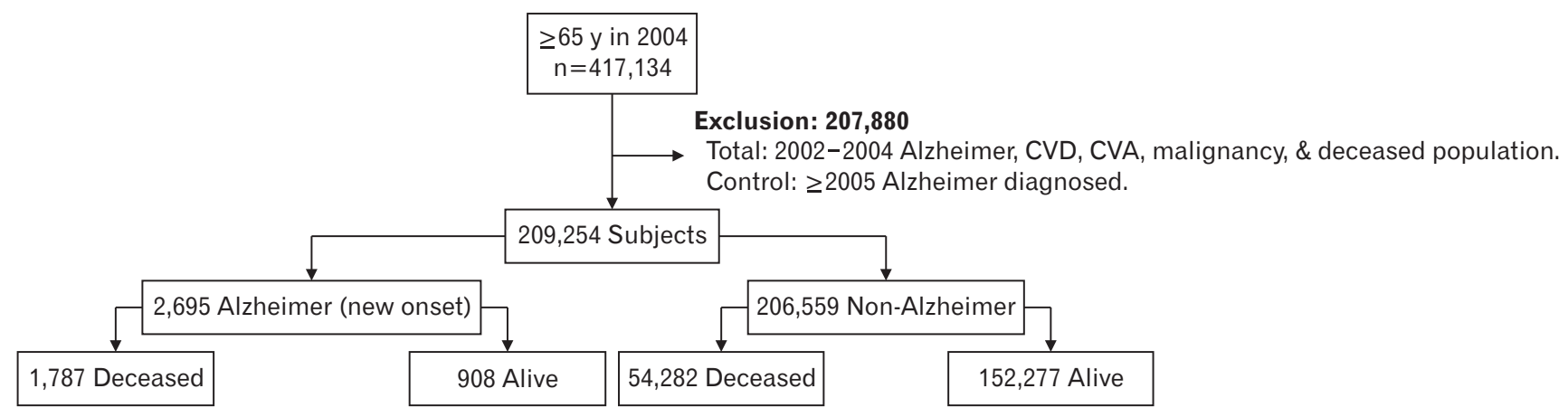

Figure 1. Flowchart of subjects from the Korean National Health Insurance Services' Senior Cohort database (2002-2013). To compare the survival of the AD group and the non- $\mathrm{AD}$ group during the observation period, those who died before the study period were excluded. The total number of included subjects was 209,254, including 2,695 who were first diagnosed with AD during the year 2004 and 206,559 non-AD subjects. The numbers of deaths were 1,787 and 54,282 in the non-AD group, respectively. AD, Alzheimer's disease; CVD, cardiovascular disease; CVA, cerebral vascular accident. 


\section{RESULTS}

\section{Demographic and Baseline Characteristics}

Out of the entire sample of 209,504 individuals, there were 2,695 (1.3\%) in the $\mathrm{AD}$ group, and 206,559 (98.7\%) in the non-AD group. Mean age in the $\mathrm{AD}$ and non- $\mathrm{AD}$ groups were $76.4 \pm 6.8$ years and $71.5 \pm 5.9$ years, respectively, and the mean age of the $\mathrm{AD}$ group was 4.9 years older. In terms of sex, $40.9 \%$ of the subjects were male and $59.1 \%$ were female. Among subjects in the $\mathrm{AD}$ group, $30.3 \%$ were male and $69.7 \%$ were female, and among subjects in the non-AD group, $41.0 \%$ were male and $59.0 \%$ were female. Thus, it was found that the proportion of women in the $\mathrm{AD}$ group was higher (Table 1). In the analysis by age, subjects were classified into one of the following four age groups: 65-69 years old, 70-74 years old, 75-79 years old, and over 80 years old. The age

Table 1. Basaline characteristics and mortalities of the cohort

\begin{tabular}{|c|c|c|c|c|c|c|}
\hline \multirow{2}{*}{ Characteristic } & \multirow{2}{*}{ Total } & \multicolumn{2}{|c|}{$A D$} & \multicolumn{2}{|c|}{ Non-AD } & \multirow{2}{*}{ P-value } \\
\hline & & Subtotal & Mortality & Subtotal & Mortality & \\
\hline Total & 209,254 & 2,695 (1.3) & 1,787 (66.3) & $206,559(98.7)$ & $54,282(26.3)$ & $<0.0001$ \\
\hline Age (y) & $71.59 \pm 6.0$ & $76.4 \pm 6.8$ & & $71.5 \pm 5.9$ & & $<0.0001$ \\
\hline Gender & & & & & & $<0.0001$ \\
\hline Male & $85,710(40.9)$ & 816 (30.3) & $619(75.9)$ & $84,786(41.0)$ & $27,453(32.4)$ & \\
\hline Female & $123,980(59.1)$ & $1,879(69.7)$ & 1,168 (62.2) & $121,773(59.0)$ & $26,829(22.0)$ & \\
\hline Age range (y) & & & & & & $<0.0001$ \\
\hline $65-69$ & 97,997 (46.8) & 473 (17.6) & 202 (42.7) & 97,524 (47.2) & $13,551(13.9)$ & \\
\hline $70-74$ & $56,522(27.0)$ & $662(24.6)$ & 353 (53.3) & $55,860(27.0)$ & $12,818(22.9)$ & \\
\hline $75-79$ & $30,113(14.4)$ & $675(25.0)$ & 465 (68.9) & 29,438 (14.3) & $11,598(39.4)$ & \\
\hline$\geq 80$ & 24,622 (11.8) & 885 (32.8) & 767 (86.7) & 23,737 (11.5) & $16,315(68.7)$ & \\
\hline Hypertension & & & & & & $<0.0001$ \\
\hline Yes & 80,479 (38.5) & $1,160(43.0)$ & 758 (65.3) & 79,319 (38.4) & 22,072 (27.8) & \\
\hline No & $128,775(61.5)$ & $1,535(57.0)$ & $1,029(67.0)$ & $127,240(61.6)$ & $32,210(25.3)$ & \\
\hline Diabetes mellitus & & & & & & 0.035 \\
\hline Yes & 32,130 (15.3) & $453(16.8)$ & 298 (65.8) & 31,677 (15.3) & $9,705(30.6)$ & \\
\hline No & $177,124(84.7)$ & 2,242 (83.2) & $1,489(66.4)$ & $174,882(84.7)$ & $44,577(25.5)$ & \\
\hline Dyslipidemia & & & & & & 0.0022 \\
\hline Yes & $12,612(6.0)$ & $200(7.4)$ & $102(51.0)$ & $12,412(6.0)$ & 2,068 (16.7) & \\
\hline No & $196,642(94.0)$ & 2,495 (92.6) & $1,685(67.5)$ & $194,147(94.0)$ & $52,214(26.9)$ & \\
\hline Income level* & & & & & & 0.0003 \\
\hline Very low & 2,498 (1.2) & $44(1.6)$ & $38(86.4)$ & $2,454(1.2)$ & $866(35.3)$ & \\
\hline Low & 23,625 (11.3) & 247 (9.2) & $167(67.6)$ & 23,378 (11.3) & 6,622 (28.3) & \\
\hline Mid to high & 183,131 (87.5) & 2,404 (89.2) & 1,582 (65.8) & $180,727(87.5)$ & $46,794(25.9)$ & \\
\hline
\end{tabular}

Values are presented as number (\%) or mean \pm standard deviation.

AD, Alzheimer's disease.

*Devided into following three categories: very low (income decile=0), low (income decile=1), and mid to high (income decile $\geq 2$ ).

Table 2. Causes of death

\begin{tabular}{|c|c|c|c|c|c|c|}
\hline \multirow{2}{*}{ Variable } & \multicolumn{3}{|c|}{$A D$} & \multicolumn{3}{|c|}{ Non-AD } \\
\hline & Total & Male & Female & Total & Male & Female \\
\hline Dementia (F00-F03, G30) & $374(20.9)$ & $112(18.1)$ & $262(22.4)$ & - & - & - \\
\hline CVA $(160-69$, G46) & $269(15.1)$ & $103(16.6)$ & $166(14.2)$ & 6,697 (12.3) & $3,054(11.1)$ & 3,643 (13.6) \\
\hline Senescence (R54) & 238 (13.3) & $60(9.7)$ & 178 (15.2) & $7,272(13.4)$ & $2,546(9.3)$ & $4,726(17.6)$ \\
\hline Cancer (C00-C97) & $113(6.3)$ & $56(9.0)$ & $57(4.9)$ & $14,938(27.5)$ & $9,203(33.5)$ & $5,731(21.4)$ \\
\hline Lung (C33, C34) & $22(1.2)$ & $14(2.3)$ & $8(0.7)$ & $4,087(7.5)$ & $3,021(11.0)$ & $1,066(4.0)$ \\
\hline Stomach (C16) & $17(1.0)$ & $8(1.3)$ & $9(0.8)$ & $2,207(4.1)$ & $1,396(5.1)$ & $811(3.0)$ \\
\hline Colon (C18-C21) & $14(0.8)$ & $6(1.0)$ & $8(0.7)$ & $1,600(2.9)$ & $834(3.0)$ & $766(2.9)$ \\
\hline Liver (C22) & $12(0.7)$ & $7(1.1)$ & $5(0.4)$ & $1,660(3.1)$ & $1,030(3.8)$ & $630(2.3)$ \\
\hline Pneumonia (J12-J18, J69) & $101(5.7)$ & $41(6.6)$ & $60(5.1)$ & $1,941(3.6)$ & $1,006(3.7)$ & 935 (3.5) \\
\hline Diabetes (E10-14) & $91(5.1)$ & $24(3.9)$ & $67(5.7)$ & $2,543(4.7)$ & $1,145(4.2)$ & $1,398(5.2)$ \\
\hline CVD (I20-I25) & $85(4.8)$ & $24(3.9)$ & $61(5.2)$ & $2,850(5.3)$ & $1,252(4.6)$ & $1,598(6.0)$ \\
\hline Missing & $29(1.6)$ & $6(1.0)$ & $23(2.0)$ & $623(1.1)$ & $238(0.9)$ & 385 (1.4) \\
\hline Total & $1,787(100.0)$ & $619(100.0)$ & $1,168(100.0)$ & $54,282(100.0)$ & $27,453(100.0)$ & $26,829(100.0)$ \\
\hline
\end{tabular}

Values are presented as number (\%).

AD, Alzheimer's disease; CVA, cerebrovascular accident; CVD, cardiovascluar disease. 
composition ratios were $46.8 \%, 27.0 \%, 14.4 \%, 11.8 \%$ in the entire sample; $17.6 \%, 24.6 \%, 25.0 \%$, and $32.8 \%$, in the AD group; and $47.2 \%$, $27.0 \%, 14.3 \%$, and $11.5 \%$ in the non-AD group. Therefore, unlike in the non-AD group, it was found that the composition ratio of individuals in the $\mathrm{AD}$ group increased with age. In the analysis of the three most common chronic diseases (hypertension, diabetes, and dyslipidemia), all prevalence rates in the $\mathrm{AD}$ group were relatively higher than those in the non-AD group. In the income analysis, composition ratios of the non-AD group and the total sample were similar, whereas the $\mathrm{AD}$ group showed slight differences from the non-AD group and the entire sample: $1.6 \%$ of subjects were in the very low-income bracket (income decile $=0$, medical aid), $9.2 \%$ were in the low-income bracket (income decile $=1$ ), and $89.2 \%$ were in the mid- to high-income bracket (income decile 2). These findings indicate that the proportion of subjects in the
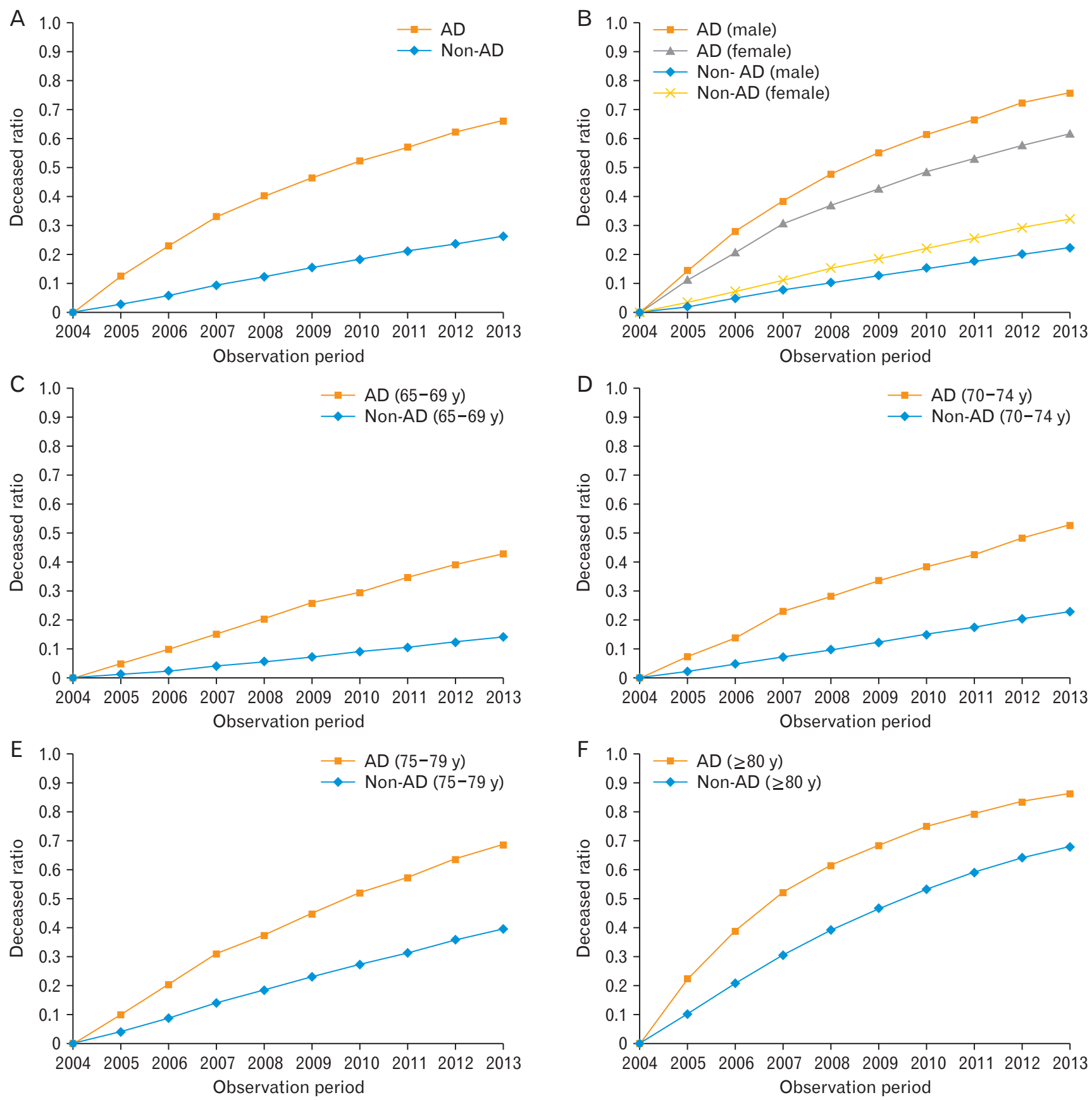

Figure 2. Differences in survival time between the $A D$ and the non-AD groups, as determined using the Kaplan-Meier method. In the graphs, the $x$-axis represents the number of survival times converted into years, and the $y$-axis represents the number of deaths corresponding to each survival period. (A) Graph $A$ shows the results of the comparison of deaths between the $A D$ and the non-AD groups. (A) Graph $A$ compares the survival times of the $A D$ group with those of the non- $A D$ group. (B) Graph $B$ compares survival time by gender, and the remaining graphs $(C-F)$ show the comparison of age-specific survivals. Each statistical significance level was $P<0.0001$. $A D$, Alzheimer's disease. 
very low-income bracket in the $\mathrm{AD}$ group was higher than that of the non-AD group.

\section{Deaths among the Study Population}

The total number of deaths in the study period was 56,069. The mortality rate in the $\mathrm{AD}$ group was $66.3 \%(1,787$ out of 2,695$)$ and the mortality rate in the non-AD group was $26.3 \%$ (54,282 out of 206,559$)$. Results of the analysis by sex indicated that the mortality rate of male subjects ( $\mathrm{AD}$ group $75.9 \%$, non-AD group $32.4 \%$ ) was higher than that of female subjects (AD group 62.2\%, non-AD group 22.0\%) in both groups. The results of the age-specific analysis indicated that in both groups, mortality increased with age. Overall, in the analyses of gender and age, mortality rates in the $\mathrm{AD}$ group, were generally higher than those in the non-AD group (Table 1). In the analysis of the three most common accompanying chronic diseases, it was found that subjects with hypertension, diabetes, and dyslipidemia in the $\mathrm{AD}$ group were less likely to die than subjects with the same diseases in the non-AD group. On the other hand, except for dyslipidemia, in the non-AD group, the mortality rates were higher in subjects with hypertension and diabetes. In the income analysis, the mortality rates of subjects in the very low-income bracket ( $\mathrm{AD} 86.4 \%$, non- $\mathrm{AD} 35.3 \%$ ) were higher than those of subjects in the other two income brackets in both groups, and the difference in the mortality rates, between subjects receiving medical aid (very low-income bracket) and those with health insurance (low or mid- to high-income bracket) was greater in the $\mathrm{AD}$ group.

\section{Causes of Death}

In the comparison of the causes of death other than dementia, CVA was found to be the most frequent cause other than dementia (15.1\%) in the $\mathrm{AD}$ group, followed by senescence (13.3\%), malignant neoplasm (6.3\%), pneumonia (5.7\%), diabetes (5.1\%), and CVD (4.8\%) (Table 2). In the non-AD group, the most frequent causes of death other than dementia were malignant neoplasm $27.5 \%$, followed by senescence (13.4\%), CVA (12.3\%), CVD (5.3\%), diabetes (4.7\%), and pneumonia (3.6\%).

When the malignant neoplasms were analyzed in detail, lung cancer ( $\mathrm{AD}$ group $1.2 \%$, non-AD group $7.5 \%$ ) was found to be the most frequent type of neoplasm among the causes of death other than dementia, and stomach cancer (AD group 1.0\%, non-AD group $4.1 \%$ ) was found to be the second most frequent type. In the analysis of the causes of death by gender and age, the mortality rates in the $\mathrm{AD}$ group were generally higher than those in the non-AD group (Table 2).

\section{Survival Rates}

Results of the comparison of survival curves using the Kaplan-Meier method, suggested that deaths in the $\mathrm{AD}$ group were generally higher than those in the non-AD group. The proportion of deceased females in the $\mathrm{AD}$ group was even higher than the proportion of deceased males in the non-AD group (Figure 2).

During the observation period (2005-2013), the mean survival interval of the $\mathrm{AD}$ group was $5.3 \pm 3.3$ years, which was about 2.4 years shorter than that of the non-AD group, which was $7.8 \pm 2.4$ years. In addition, in the analysis by sex, the mean survival intervals of males (AD group $4.7 \pm 3.2$ years, non- $\mathrm{AD}$ group $7.5 \pm 2.6$ years) were shorter than those of females (AD group 5.6 \pm 3.3 years, non-AD group $8.0 \pm 2.3$ years), in both groups. More precisely, the difference in the survival interval between males and females in the AD group was approximately

Table 3. Survival interval, during observation period (from the initial diagnosis, year)

\begin{tabular}{|c|c|c|c|c|c|c|c|}
\hline \multirow{3}{*}{ Variable } & \multicolumn{4}{|c|}{$A D$} & \multicolumn{2}{|c|}{ Non-AD } & \multirow{3}{*}{ P-value } \\
\hline & \multicolumn{2}{|c|}{ During observation period } & \multicolumn{2}{|c|}{ From the initial diagnosis } & \multirow{2}{*}{ Median } & \multirow{2}{*}{ Average $\pm S D$} & \\
\hline & Median & Average $\pm S D$ & Median & Average $\pm S D$ & & & \\
\hline Total & 5.5 & $5.3 \pm 3.3$ & 6.1 & $5.9 \pm 3.3$ & 9.0 & $7.8 \pm 2.4$ & $<0.0001$ \\
\hline Gender & & & & & & & $<0.0001$ \\
\hline Male & 4.2 & $4.7 \pm 3.2$ & 4.9 & $5.3 \pm 3.2$ & 9.0 & $7.5 \pm 2.6$ & \\
\hline Female & 6.3 & $5.6 \pm 3.3$ & 7.0 & $6.2 \pm 3.3$ & 9.0 & $8.0 \pm 2.3$ & \\
\hline Age (y) & & & & & & & $<0.0001$ \\
\hline $65-69$ & 9.0 & $7.0 \pm 2.9$ & 9.2 & $7.6 \pm 2.9$ & 9.0 & $8.4 \pm 1.7$ & \\
\hline $70-74$ & 8.3 & $6.3 \pm 3.2$ & 8.9 & $6.9 \pm 3.1$ & 9.0 & $8.0 \pm 2.2$ & \\
\hline $75-79$ & 5.5 & $5.4 \pm 3.2$ & 6.2 & $6.0 \pm 3.2$ & 9.0 & $7.2 \pm 2.8$ & \\
\hline$\geq 80$ & 2.8 & $3.7 \pm 3.0$ & 3.4 & $4.3 \pm 3.1$ & 5.4 & $5.4 \pm 3.2$ & \\
\hline \multicolumn{8}{|l|}{ Comorbidity* $^{*}$} \\
\hline Diabetes & 4.6 & $5.0 \pm 3.3$ & 5.3 & $5.6 \pm 3.3$ & 9.0 & $7.5 \pm 2.6$ & $<0.0001$ \\
\hline Hypertension & 5.8 & $5.4 \pm 3.3$ & 6.5 & $6.0 \pm 3.4$ & 9.0 & $7.7 \pm 2.5$ & $<0.0001$ \\
\hline Dyslipidemia & 9.0 & $6.9 \pm 2.8$ & 9.1 & $7.5 \pm 2.9$ & 9.0 & $8.4 \pm 1.7$ & 0.0002 \\
\hline \multicolumn{8}{|l|}{ Income level $^{\dagger}$} \\
\hline Very low & 3.2 & $4.0 \pm 3.1$ & 4.0 & $4.6 \pm 3.1$ & 9.0 & $7.2 \pm 2.8$ & $<0.0001$ \\
\hline Low & 4.6 & $4.9 \pm 3.4$ & 5.2 & $5.5 \pm 3.4$ & 9.0 & $7.7 \pm 2.5$ & $<0.0001$ \\
\hline Mid to high & 5.6 & $5.4 \pm 3.3$ & 6.2 & $6.0 \pm 3.3$ & 9.0 & $7.8 \pm 2.4$ & $<0.0001$ \\
\hline
\end{tabular}

AD, Alzheimer's disease; SD, standard deviation.

*Frequent accompanying three disease (hypertension, diabetes, and dyslipidemia). 'Devided into following three categories: very low (income decile=0), low (income decile=1), and mid to high (income decile $\geq 2$ ). 
0.9 years, greater than in the non-AD group (Table 3 ).

In the age-group analysis, survival time significantly decreased with age, and survival time in the over-80-year-old group was shorter than that of the 65- to 69-year-old group, by 3.3 years in the AD group and 3.1 years in the non-AD group. In the analysis of the three most frequent major chronic diseases, the survival times of the patients with diabetes were the shortest ( $\mathrm{AD}$ group 5.0 \pm 3.3 years, non- $\mathrm{AD}$ group $7.5 \pm 2.6$ years) in both groups. In contrast, the survival times of the patients with dyslipidemia were the longest (AD group 6.9 \pm 2.8 years, non-AD group $8.4 \pm 1.7$ years).

In the income analysis, the survival times of the subjects in the very low-income bracket were shorter than those of subjects in the other income brackets in both groups, but the difference between survival times of the subjects in the very low-income bracket and the mid- to high-income bracket in the $\mathrm{AD}$ group was about 1.4 years, which was greater than that of subjects in these two income brackets in the non$\mathrm{AD}$ group.

In the $\mathrm{AD}$ group, when the survival was separately calculated from the date of being first diagnosed with $\mathrm{AD}$, the mean survival interval was $5.9 \pm 3.3$ years, and the male survival interval was $5.3 \pm 3.3$ years, about 0.9 years shorter than that $(6.2 \pm 3.3$ ) of females (Table 3 ).

\section{Covariates}

Results of the mortality risk analysis using the Cox proportional-hazard model (HR, 95\% CI), indicated that subjects in the AD group had a HR of 3.7 (95\% CI, 3.53-3.88,), and after adjustment with variables (i.e., gender, age, income level, and the three most common major chronic diseases), it was 2.5 (95\% CI, 2.38-2.62). Therefore, it was found that the $\mathrm{AD}$ group had a 2.5 -fold higher risk of death than the non-AD group. The analysis of stratification using gender, age, income level, and three most common major chronic diseases (i.e., hypertension, diabetes, and dyslipidemia) showed similar results. In sum, the analysis of stratification showed that the risk of death in the $\mathrm{AD}$ group was higher than in the non-AD group (Table 4).

\section{DISCUSSION}

\section{Survival Analysis}

This study was based on the National Health Insurance Services' Senior Cohort database (2002-2013), and compared the survival of subjects in the $\mathrm{AD}$ group with that of subjects in the non-AD group. In particular, our study examined the independent impact of $\mathrm{AD}$ itself on mortality risk. With regard to mortality risk, patients with $\mathrm{AD}$ had an HR of 2.5 (adjusted) in this study, which was slightly higher than the HR of 1.82 found in a recent Korean study on patients with all types of dementia. ${ }^{10)}$ However, the results (HR, 1.7-2.9) of foreign studies analyzing $\mathrm{AD}$ groups showed similar findings to both. ${ }^{11-14)}$ In the present study, stratification analyses were conducted for each variable to examine the effect of $\mathrm{AD}$ on survival in more detail. It was found that the overall risks of death in the $\mathrm{AD}$ group were higher than in the non- $\mathrm{AD}$ group.
Table 4. Cox propotional hazard ratio by multivariable and stratification

\begin{tabular}{|c|c|c|c|}
\hline Variable & Category & $\begin{array}{c}\text { Hazard ratio } \\
\text { (95\% condfidence interval) }\end{array}$ & P-value \\
\hline \multirow[t]{2}{*}{ Unadjusted } & $A D$ & $3.7(3.53-3.88)$ & $<0.0001$ \\
\hline & Non-AD & 1.0 & \\
\hline \multirow[t]{2}{*}{ Adjusted } & $A D$ & 2.5 (2.38-2.62) & $<0.0001$ \\
\hline & Non-AD & 1.0 & \\
\hline \multicolumn{4}{|l|}{ Gender* } \\
\hline \multirow[t]{2}{*}{ Male } & $A D$ & $2.7(2.51-2.95)$ & $<0.0001$ \\
\hline & Non-AD & 1.0 & \\
\hline \multirow[t]{2}{*}{ Female } & $A D$ & $2.3(2.19-2.46)$ & $<0.0001$ \\
\hline & Non-AD & 1.0 & \\
\hline \multicolumn{4}{|l|}{ Age $(y)^{\dagger}$} \\
\hline \multirow[t]{2}{*}{$\geq 80$} & $A D$ & $1.9(1.79-2.07)$ & $<0.0001$ \\
\hline & Non-AD & 1.0 & \\
\hline \multirow[t]{2}{*}{$75-79$} & $A D$ & $2.6(2.33-2.81)$ & $<0.0001$ \\
\hline & Non-AD & 1.0 & \\
\hline \multirow[t]{2}{*}{$70-74$} & $A D$ & $3.2(2.92-3.60)$ & $<0.0001$ \\
\hline & NonAD & 1.0 & \\
\hline \multirow[t]{2}{*}{$65-69$} & $A D$ & $4.1(3.56-4.71)$ & $<0.0001$ \\
\hline & Non-AD & 1.0 & \\
\hline \multicolumn{4}{|l|}{ Comorbidity $^{\ddagger}$} \\
\hline \multirow[t]{2}{*}{ Diabetes } & $A D$ & $2.3(1.89-2.85)$ & $<0.0001$ \\
\hline & Non-AD & 1.0 & \\
\hline \multirow[t]{2}{*}{ Hypertenion } & $A D$ & $2.4(2.23-2.66)$ & $<0.0001$ \\
\hline & Non-AD & 1.0 & \\
\hline \multirow[t]{2}{*}{ Dyslipidemia } & $A D$ & $2.6(1.67-3.94)$ & $<0.0001$ \\
\hline & Non-AD & 1.0 & \\
\hline \multicolumn{4}{|l|}{ Income level $\left.\right|^{\S . \|}$} \\
\hline \multirow[t]{2}{*}{ Very low } & $A D$ & $2.5(2.35-2.60)$ & $<0.0001$ \\
\hline & Non-AD & 1.0 & \\
\hline \multirow[t]{2}{*}{ Low } & $A D$ & $2.7(2.28-3.10)$ & $<0.0001$ \\
\hline & Non-AD & 1.0 & \\
\hline \multirow[t]{2}{*}{ Mid to high } & $A D$ & $3.3(2.33-4.54)$ & $<0.0001$ \\
\hline & Non-AD & 1.0 & \\
\hline
\end{tabular}

$A D$, Alzheimer's disease.

*Variables for stratification adjustment: age, income level and frequent accompanying diseases such as hypertension, diabetes, and dyslipidemia. 'Variables for stratification adjustment: gender, income level and frequent accompanying diseases such as hypertension, diabetes, and dyslipidemia. 'Variables for stratification adjustment: gender age and income level. ${ }^{\S}$ Variables for stratification adjustment: gender, age and frequent accompanying diseases such as hypertension, diabetes, and dyslipidemia. "Divided into three categories: very low (income decile=0), low (income decile=1), and mid to high (income decile $\geq 2$ ).

During the observation period (2005-2013), the survival intervals of the $\mathrm{AD}$ and non- $\mathrm{AD}$ groups were compared, and the survival interval of the $\mathrm{AD}$ group was about 2.4 years shorter. However, when only the survival interval after being first diagnosed with $\mathrm{AD}$ was calculated, the overall average was 5.9 years, and the survival interval in males was on average 0.9 years shorter than that in females. This suggested that the survival interval after being diagnosed with $\mathrm{AD}$ was shorter than the average of 9.7 years reported in a previous domestic study. ${ }^{15)}$ However, the finding was similar to those of foreign studies (Ganguli et al. ${ }^{12)} 6.39$ years, Fitzpatrick et al ${ }^{16)} 7.1$ years) under similar conditions. A possible explanation for the different findings may the age of the subjects. Unlike the previous Korean studies that included subjects with early onset dementia, subjects in the present study were 65 years of age or old- 
er. Therefore, there was a difference in population composition. The mean age of the subjects was 76.4 years, which was higher than in the previous studies. In addition, the percentage of the population over 80 years old, who had many complex factors to consider (such as, comorbidity, functional impairments, and severity of dementia) was as high as $32.8 \%$.

When comparing the causes of death other than dementia between the $\mathrm{AD}$ group and the non- $\mathrm{AD}$ group, in general, CVA was the most frequent cause (15.1\%) in the $\mathrm{AD}$ group, and malignant neoplasm was the most frequent $(27.5 \%)$ in the non- $\mathrm{AD}$ group. Interestingly, there was a significant difference in malignancies between the $\mathrm{AD}$ and non$\mathrm{AD}$ groups. It could be derived from the difference in age composition. The higher mean age in the $\mathrm{AD}$ group was likely to be survived from the malignancies and may indicate survival effects. In the $\mathrm{AD}$ group, dementia was the most common cause of death at $20.9 \%$, but this rate was less than the $36 \%$ reported in the previous Korean study (Table 2). In addition, senescence (10.4\%), the second most common cause of death in the previous study, accounted for $13.3 \%$ in the present study, which was lower than that of CVA (15.1\%) in the AD group. ${ }^{15)}$ This could be the result of differences in population composition, as described above, and also because of the proportion of women (69.7\%), who had a longer survival and lower mortality risk in the present study. In foreign studies, CVD (Fitzpatrick et al. ${ }^{16)} 19 \%$, Ganguli et al. ${ }^{12)}$ $47.5 \%$ ) was the most common cause of death, but in the present study, it was $4.8 \%$. It was also $6.1 \%$ in the domestic study. The incongruencies may be due to cultural differences. ${ }^{17)}$

The present study also found that the age at diagnosis of $\mathrm{AD}$ was the most important factor affecting the increase in mortality and the shortening of the survival interval. ${ }^{18)}$ However, we also found that in both groups, mortality increased sharply with age. This finding may be due to the effects of multimorbidity on the survival of elderly patients as age increases. ${ }^{19-23)}$ Survival time and mortality rates were significantly better in the patients with dyslipidemia. This finding may be due the relationship between malnutrition and death, or body mass index and survival, but further research is needed. ${ }^{24-27)}$

\section{Limitations and Strengths}

The limitations of this study are as follows: First, this study excluded the deceased population from the baseline year 2004, which included some individuals diagnosed with $\mathrm{AD}$. In this case, the population could have had greater mortality risk and shorter survival periods. Therefore, there is a possibility that some bias may have occurred. Second, as mentioned above, the higher mean age in the $\mathrm{AD}$ group, like other studies, may indicate survival from diseases with high risk of death, so this could also indicate survival-effect bias. Third, further research on the comorbid factors with various diseases and on the lifestyles of the patients with $\mathrm{AD}$, which were not investigated in this study, are needed.

However, this study has several strengths. First, it was based on the National Health Insurance Services' Senior Cohort database (20022013), which is a good representation of the Korean general popula- tion. Second, this study covered a larger population than in previous studies. Third, the accuracy of the study was high because there were few missing values in the cohort data. Finally, there have been few previous Korean studies that have directly compared the survival of $\mathrm{AD}$ and non-AD groups, and have analyzed survival from the onset of $\mathrm{AD}$.

\section{Conclusion}

Overall, AD has a large, independent impact on survival, and can shorten life expectancy. The prevalence of $\mathrm{AD}$ in Korea is rapidly rising, and it is necessary to have proper awareness of the clinician and to respond accordingly. More diverse research on $\mathrm{AD}$ and a more comprehensive understanding of the disease can promote healthy aging and better quality of life in the elderly.

\section{CONFLICT OF INTEREST}

No potential conflict of interest relevant to this article was reported.

\section{ORCID}

Tae Ho Huh: https://orcid.org/0000-0002-2431-1802

Jong Lull Yoon: https://orcid.org/0000-0001-8931-0256

Jung Jin Cho: https://orcid.org/0000-0001-8871-8858

Mee Young Kim: https://orcid.org/0000-0002-1724-2175

Young Soo Ju: https://orcid.org/0000-0003-2829-9457

\section{REFERENCES}

1. World Health Organization. Towards a dementia plan: a WHO guide. Geneva: World Health Organization; 2018.

2. Kisler K, Nelson AR, Montagne A, Zlokovic BV. Cerebral blood flow regulation and neurovascular dysfunction in Alzheimer disease. Nat Rev Neurosci 2017;18:419-34.

3. Folch J, Ettcheto M, Petrov D, Abad S, Pedros I, Marin M, et al. Review of the advances in treatment for Alzheimer disease: strategies for combating $\beta$-amyloid protein. Neurologia 2018;33:47-58.

4. Tramutola A, Lanzillotta C, Perluigi M, Butterfield DA. Oxidative stress, protein modification and Alzheimer disease. Brain Res Bull 2017;133:88-96.

5. Kim SH, Han SH. Prevalence of dementia among the South Korean population. J Korean Diabetes 2012;13:124-8.

6. Wu YT, Brayne C, Matthews FE. Prevalence of dementia in East Asia: a synthetic review of time trends. Int J Geriatr Psychiatry 2015;30:793801.

7. National Institute of Dementia. Korean dementia observatory 2017. Seongnam: National Institute of Dementia; 2018.

8. Lee DW, Seong SJ. Korean national dementia plans: from 1st to 3rd. J Korean Med Assoc 2018;61:298-303.

9. Ferri CP, Prince M, Brayne C, Brodaty H, Fratiglioni L, Ganguli M, et al. Global prevalence of dementia: a Delphi consensus study. Lancet 2005;366:2112-7.

10. Bae JB, Han JW, Kwak KP, Kim BJ, Kim SG, Kim JL, et al. Is dementia more fatal than previously estimated?: a population-based prospec- 
tive cohort study. Aging Dis 2019;10:1-11.

11. Aevarsson O, Svanborg A, Skoog I. Seven-year survival rate after age 85 years: relation to Alzheimer disease and vascular dementia. Arch Neurol 1998;55:1226-32.

12. Ganguli M, Dodge HH, Shen C, Pandav RS, DeKosky ST. Alzheimer disease and mortality: a 15-year epidemiological study. Arch Neurol 2005;62:779-84.

13. Scarmeas N, Luchsinger JA, Mayeux R, Stern Y. Mediterranean diet and Alzheimer disease mortality. Neurology 2007;69:1084-93.

14. Wilson RS, Aggarwal NT, Barnes LL, Bienias JL, Mendes de Leon CF, Evans DA. Biracial population study of mortality in mild cognitive impairment and Alzheimer disease. Arch Neurol 2009;66:767-72.

15. Go SM, Lee KS, Seo SW, Chin J, Kang SJ, Moon SY, et al. Survival of Alzheimer's disease patients in Korea. Dement Geriatr Cogn Disord 2013;35:219-28.

16. Fitzpatrick AL, Kuller LH, Lopez OL, Kawas CH, Jagust W. Survival following dementia onset: Alzheimer's disease and vascular dementia. J Neurol Sci 2005;229-230:43-9.

17. GBD 2013 Mortality and Causes of Death Collaborators. Global, regional, and national age-sex specific all-cause and cause-specific mortality for 240 causes of death, 1990-2013: a systematic analysis for the Global Burden of Disease Study 2013. Lancet 2015;385:117-71.

18. Waring SC, Doody RS, Pavlik VN, Massman PJ, Chan W. Survival among patients with dementia from a large multi-ethnic population. Alzheimer Dis Assoc Disord 2005;19:178-83.

19. Nunes BP, Flores TR, Mielke GI, Thume E, Facchini LA. Multimorbidity and mortality in older adults: a systematic review and meta-analy- sis. Arch Gerontol Geriatr 2016;67:130-8.

20. Barnett K, Mercer SW, Norbury M, Watt G, Wyke S, Guthrie B. Epidemiology of multimorbidity and implications for health care, research, and medical education: a cross-sectional study. Lancet 2012;380:3743.

21. Vassilaki M, Aakre JA, Cha RH, Kremers WK, St Sauver JL, Mielke MM, et al. Multimorbidity and risk of mild cognitive impairment. J Am Geriatr Soc 2015;63:1783-90.

22. Garcia-Ptacek S, Kareholt I, Cermakova P, Rizzuto D, Religa D, Eriksdotter M. Causes of death according to death certificates in individuals with dementia: a cohort from the Swedish dementia registry. J Am Geriatr Soc 2016;64:e137-42.

23. McCormick WC, Kukull WA, van Belle G, Bowen JD, Teri L, Larson EB. Symptom patterns and comorbidity in the early stages of Alzheimer's disease. J Am Geriatr Soc 1994;42:517-21.

24. Faxen-Irving G, Basun H, Cederholm T. Nutritional and cognitive relationships and long-term mortality in patients with various dementia disorders. Age Ageing 2005;34:136-41.

25. Jang H, Kim JH, Choi SH, Lee Y, Hong CH, Jeong JH, et al. Body mass index and mortality rate in Korean patients with Alzheimer's disease. J Alzheimers Dis 2015;46:399-406.

26. Prince M, Albanese E, Guerchet M, Prina M. Nutrition and dementia: a review of available research. London: Alzheimer's Disease International (ADI); 2014.

27. Kim H, Yoon JL, Lee A, Jung Y, Kim MY, Cho JJ, et al. Prognostic effect of body mass index to mortality in Korean older persons. Geriatr Gerontol Int 2018;18:538-46. 